\title{
EDITORIAL
}

\section{Dissemination of science and technology findings}

The year 2018 marks 50 years of celebration of science at the National Science Foundation. The Journal of the National Science Foundation (JNSF) joins this celebration by publishing the September issue with a significantly increased number of articles.

The Journal of the National Science Foundation of Sri Lanka serves the purpose of disseminating science and technology findings by researchers. This journal had its origin in the National Science Council (NSC) of Sri Lanka. The first volume was published in 1972. This journal published manuscripts that included Research Articles, Reviews, and Short Communications in all fields of science and technology. It is noteworthy that the Journal accepted manuscripts in Sinhala, Tamil or English. The Journal of the National Science Council had an Editorial Board consisting of a Chairman, and ten (10) members representing various fields of science and technology. The scientists and technologists of today are indebted to the NSC and its Editorial Board members who gave the leadership to enable the science and technology findings to be published in a local journal. Some of the original Editorial Board members like Dr C.R. Panabokke, Dr R.O.B. Wijesekera and Prof. P.W. Epasinghe still continue their interest in the Journal. This is highly appreciated.

In 1981, the Natural Resources, Energy and Science Authority (NARESA) was established as the successor to the NSC. NARESA continued the good work of the NSC with regard to publishing the Journal continuously totaling a period of 27 years.

In 1999, the Journal was named the Journal of the National Science Foundation (JNSF) of Sri Lanka and has published 19 volumes up to date. The total number of volumes of the Journal published to date by the NSC, NARESA and the NSF adds up to 46.

The JNSF currently publishes four quarterly issues per volume in March, June, September and December of each year. The Journal publishes Research Articles, Research Communications, Reviews and Correspondence in all fields of science and technology. The JNSF is available in print as well as online. The JNSF is indexed in the Science Citation Index Expanded, Journal Citation Reports/Science Edition, BIOSIS Previews, Zoological Record, Biological Abstracts, Ulrich's, AGRICOLA, and EBSCOhost. Since 2013, the JNSF is an open-access Journal and now receives over 250 submissions a year from both local and foreign authors. The latter includes authors from over 25 countries.

It is of great concern that the number of local submissions show a decreasing trend while the number of foreign submissions show an increasing trend.

The JNSF currently has an Editorial Board consisting of ten (10) members, and an International Advisory Board of nine (09) members.

The $46^{\text {th }}$ volume of the JNSF is published in 2018 . Forty six years of continuous publishing of the Journal has been no easy task. In this task, we owe deep gratitude to all the past and present staff of the NSF editorial unit, the panel of reviewers and the Editorial Board. They have contributed immensely to the success of the Journal. The most important group in this endeavor has been the researchers in all fields of science and technology who submitted their findings to the Journal over the past 46 years. I salute them and hope to receive more submissions in the years to come particularly from the young scientists and technologists of the country.

Nalini Ratnasiri 